\title{
Routine surgical videothoracoscopy as the first step of the planned resection for lung cancer
}

\author{
Contardo Vergani, MD, FACS, Federico Varoli, MD, FACS, Luca Despini, MD, Sergio Harari, MD, \\ Enrico Mozzi, MD, and GianCarlo Roviaro, MD, FACS
}

Objectives: Notwithstanding preoperative staging, a number of procedures still end in an exploratory thoracot-
omy as a result of unexpected findings. The aim of this work is to evaluate the validity of routine videothoraco-
scopy, performed as the first step of every planned resection for non-small cell lung cancer, to assess tumor
resectability and feasibility of the resection through thoracoscopy.

\begin{abstract}
Methods and Results: From November 1991 to December 2007, in our department, 1306 patients with nonsmall cell lung cancer, judged operable at conventional staging, underwent videothoracoscopy before the operation. Thoracoscopy revealed inoperability in $58(4.4 \%)$ patients, mostly owing to pleural dissemination $(2.5 \%)$ or mediastinal infiltration (1.7\%). In the remaining 1248 (95.6\%), thoracoscopy did not reveal inoperability. Of these, $449(34.4 \%)$ underwent thoracoscopic resection. The other $799(61.2 \%)$ underwent thoracotomy: 767 underwent resection, but $32(2.5 \%)$ had an exploratory thoracotomy. Thoracoscopy had suggested unresectability in $7(0.5 \%)$ patients, had been incompletely carried out in $4(0.3 \%)$, and was unfeasible in $21(1.6 \%)$ owing to insurmountable technical reasons. In our previous series from 1980 to 1991 the exploratory thoracotomy rate had been $11.6 \%$. In the present series, after the introduction of routine thoracoscopy in the staging process, the exploratory thoracotomy rate was $2.5 \%$. Thoracoscopy was reliable in excluding unresectability (negative predictive value 0.97$)$. The global percentage of correct staging was significantly better $(P<.0001)$ by thoracoscopy $(73.3 \%)$ than by computed tomography $(48.7 \%)$. Considering $\mathrm{T}$ descriptor, video-assisted thoracic surgery correctly matched with final pathologic staging in $96.2 \%$ of patients.
\end{abstract}

Conclusions: Routine preliminary videothoracoscopy ensured assessment of tumor resectability and feasibility of the resection through thoracoscopy and limited unnecessary thoracotomies.

Earn CME credits at

http://cme.ctsnetjournals.org

Notwithstanding recent improvement of conventional diagnostic tools and the introduction of new technologies of metabolic imaging (fluorodeoxyglucose positron emission tomography [FDG-PET] or positron emission tomography-computed tomography [PET-CT]), clinical staging is sometimes not confirmed by intraoperative findings. A considerable number of procedures still end in a mere exploratory thoracotomy, or distant metastases are unveiled only a few months after the operation. ${ }^{1-7}$ A minimally traumatic method, such as thoracoscopy, could help in decreasing

From the Department of Surgical Sciences, University of Milan \& Department of General Surgery, Ospedale Maggiore Policlinico, Mangiagalli e Regina Elena, IRCCS, Milan, Italy, and Ospedale San Giuseppe, Milan, Italy.

Received for publication July 29, 2008; revisions received March 6, 2009; accepted for publication March 29, 2009; available ahead print June 15, 2009.

Address for reprints: Contardo Vergani, MD, FACS, Department of Surgical Sciences, University of Milan \& Department of General Surgery. Ospedale Maggiore Policlinico, Mangiagalli e Regina Elena, IRCCS, Via Francesco Sforza, 35, 20122 Milano, Italy (E-mail: contardo.vergani@unimi.it).

J Thorac Cardiovasc Surg 2009; 138:1206-12

$0022-5223 / \$ 36.00$

Copyright (c) 2009 by The American Association for Thoracic Surgery doi:10.1016/j.jtcvs.2009.03.055 the number of exploratory thoracotomies, inasmuch as it ensures a direct view of the lesion and an adequate surgical exploration. In the past, preoperative thoracoscopy for staging was used only in selected cases of pleural effusion without malignant cells, to assess pleural involvement. After the initial experviences in 1991, $\mathrm{we}^{8}$ decided to perform routine thoracoscopic exploration in every patient with non-small cell lung cancer (NSCLC) judged a candidate for pulmonary resection after conventional clinical staging.

The aim of this work is to present our experience with videothoracoscopic surgical staging for lung cancer, systematically carried out as the first step of the planned surgical procedure.

\section{PATIENTS AND METHODS}

From November 1991 to December 2007, 1761 patients were admitted with a diagnosis of lung cancer. The clinical charts of the patients have been retrospectively reviewed with particular attention to preoperative staging, surgical description, postoperative course, and histologic type. Data have been entered in a dedicated database and analyzed by SPSS 16.0 software (SPSS, Inc, Chicago, Ill). Fully informed consent to the planned surgical strategy and procedure, as well as authorization to use personal data for scientific purposes, had been obtained from each patient at hospital admission or immediately before the procedure.

Preoperative staging included chest radiographs, CT scan of the thorax, upper abdomen, and brain, and bronchoscopy. Mediastinoscopy was carried out in cases of suspected N3 disease or extracapsular N2 invasion. PET scanning has been easily available to us only since 2005 and has been 


\section{Abbreviations and Acronyms \\ $\mathrm{CT}=$ computed tomography \\ FDG-PET $=$ fluorodeoxyglucose positron emission tomography \\ NSCLC = non-small cell lung cancer \\ PET = positron emission tomography \\ VATS $=$ video-assisted thoracic surgery}

performed only on selected patients with mediastinal lymph node enlargement or patients with doubtful pulmonary or distant lesions.

Clinical evaluation ruled out cancer or revealed a medical condition precluding surgery in 210 patients. In another 245 patients with confirmed lung cancer, conventional staging found an unequivocal cause of inoperability. The remaining 1306 consecutive patients with lung cancer, candidates for curative surgery after conventional staging, were submitted to videothoracoscopic exploration immediately before the planned operation (Figure 1).

\section{Technique}

$\mathrm{We}^{9}$ have already described the technical details of video-assisted thoracic surgical (VATS) exploration elsewhere. The patient, in the lateral decubitus position as for a conventional thoracotomy, is intubated with a double-lumen tube for selective lung ventilation. Three ports are inserted in the seventh intercostal space on the midaxillary line and in the fifth intercostal space, anteriorly and posteriorly, along the incision line of the possible thoracotomy. Reusable instruments are employed. Systematic exploration from the apex to the diaphragm requires the lysis of pleural adhesions and the complete mobilization of the lung by dividing the pulmonary ligament. Videothoracoscopic exploration, however, is not limited to a mere inspection of the lung and of the pleural cavity, but can also imply other more complex surgical maneuvers such as (1) exploration of the fissure to verify the feasibility of intrafissural vascular preparation,(2) opening the pericardium to verify the possibility of an intrapericardial ligature of the great vessels, or (3) thorough exploration of the mediastinum to dissect mediastinal lymph nodes. Exploration of the superior mediastinum can involve sectioning of the azygos arch.

At the end of the exploration, the surgeon decides whether the tumor is resectable and whether the resection can be accomplished by thoracoscopy or thoracotomy. Patients in whom video exploration is not possible or patients with doubtful findings are converted to thoracotomy exploration. The patients whose conditions are judged operable at thoracoscopy are submitted to formal resection under videothoracoscopy or thoracotomy immediately after thoracoscopy exploration.

\section{RESULTS}

Out of the present series of 1306 patients, VATS exploration revealed causes of inoperability in $58(4.4 \%)$ patients, whereas in the remaining $1248(95.6 \%)$ no sure causes of unresectability were found. Among the 58 patients declared inoperable, videothoracoscopy revealed a small-nodule pleural dissemination without pleural effusion in $32(2.5 \%)$ and a mediastinal infiltration in $22(1.7 \%)$. In another $4(0.3 \%)$ patients in whom pneumonectomy would not have been tolerated, thoracoscopy detected the infiltration of the artery within the fissure. In the remaining 1248 patients, thoracoscopy did not reveal any cause of inoperability and the patients were submitted to surgical resection. In $449(34.4 \%)$ patients with stage I lung cancer, the resection was carried out thoracoscopically. Of these, 230 had a lobectomy with lymphadenectomy,

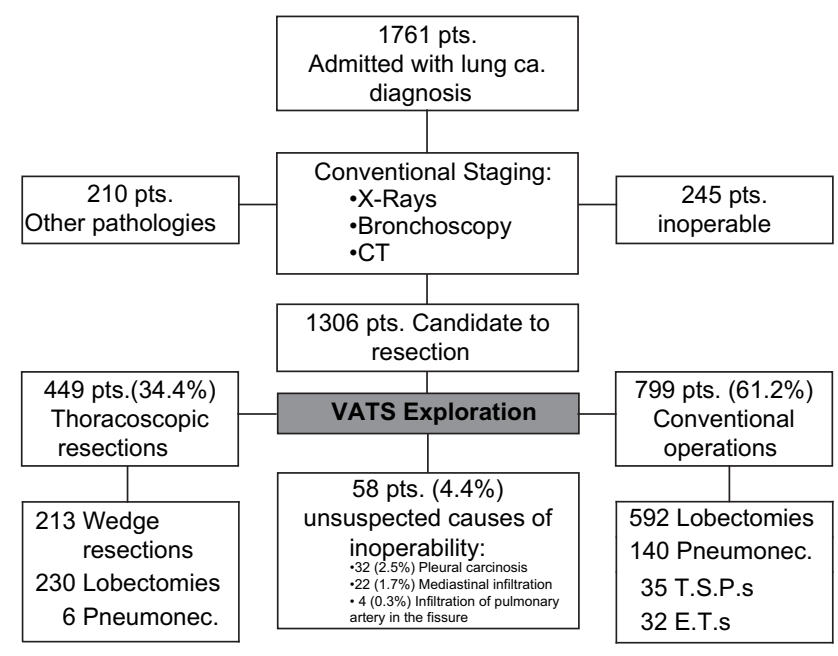

FIGURE 1. Personal experience of routine videothoracoscopic exploration carried out immediately before the planned resection from November 1991 to December 2007. CT, Computed tomography; VATS, video-assisted thoracic surgery; TSPs, tracheal sleeve pneumonectomies; ETs, exploratory thoracotomies.

6 had a video pneumonectomy, and 213 patients with poor clinical and cardiorespiratory function had a video wedge resection. The other $799(61.2 \%)$ patients in whom VATS exploration had not revealed or confirmed inoperability underwent thoracotomy. Of these, 767 patients underwent lobectomy $(\mathrm{n}=592)$, pneumonectomy $(\mathrm{n}=140)$, and tracheal sleeve pneumonectomy $(\mathrm{n}=35)$. In $32(2.5 \%)$ patients, thoracotomy revealed inoperability. In $7(0.5 \%)$ of them thoracoscopy had raised the suspicion of unresectability, but the impossibility of carrying out the resection had not been confirmed. In these cases unresectability was due to infiltration of the aorta (2 patients), intrapericardial invasion of the great vessels ( 2 patients), intrafissural involvement of the artery in 2 patients who would not have tolerated pneumonectomy, and, finally, intense peritumoral reaction in 1 young patient who had undergone neoadjuvant chemotherapy. In 21 $(1.6 \%)$, videothoracoscopic staging was impossible for technical reasons (diffuse adhesions sealing the pleural cavity in 17 and incomplete lung collapses owing to bronchial obstruction in 4$)$. In another 4 cases $(0.3 \%)$, which occurred at the beginning of our experience, videoendoscopic assessment had been inadequately conducted, and thoracotomy revealed extracapsular mediastinal lymphadenopathy ( 3 patients) or intrafissural invasion of the artery in 1 patient, not amenable to pneumonectomy. Globally, video exploration was highly reliable in excluding conditions of unresectability with a negative predictive value of 0.97 . Morbidity and mortality specifically referred to the preliminary video exploration has been absent.

With final pathologic staging used as the benchmark, the percentage of patients whose cancer was understaged, correctly staged, and overstaged by preoperative CT was $30.4 \%, 48.7 \%$, and $20.9 \%$, respectively (Figure 2 ). The global rate of understaging, correct staging, and overstaging 
A

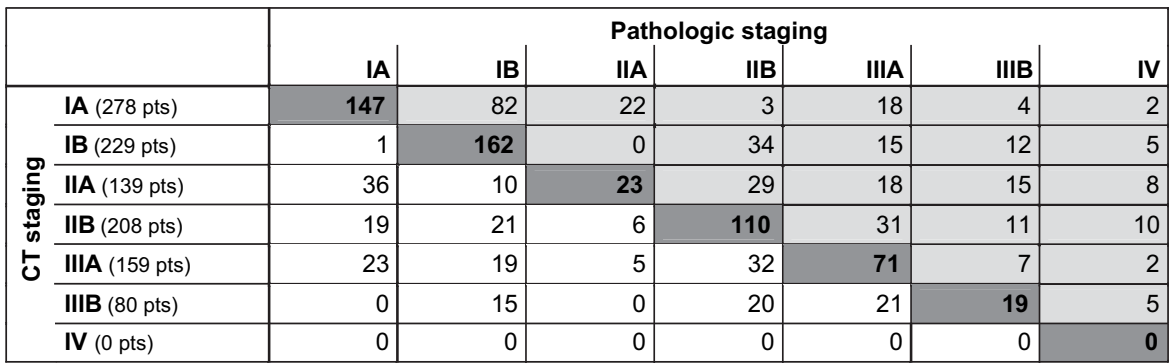

B

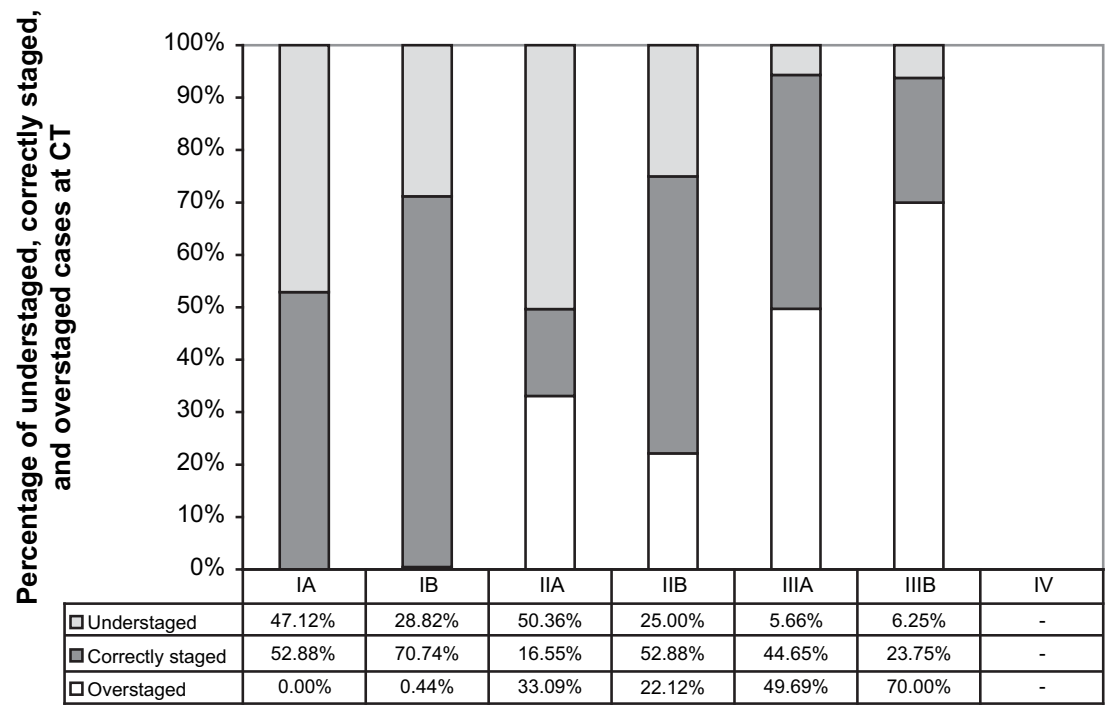

TNM stages

FIGURE 2. A, CT staging compared with final pathologic staging. Dark gray cells indicate cases correctly staged by preoperative CT, light gray cells indicate understaged cases, and white cells indicate overstaged cases. B. The percentage of correctly staged, understaged, and overstaged cases for each TNM stage identified by $\mathrm{CT}$, using the final pathologic staging as the benchmark. $C T$, Computed tomography.

by thoracoscopy was $24.4 \%, 73.3 \%$, and $0 \%$, respectively. In $1.9 \%$ of cases VATS was not feasible. The global accuracy rate was $73.3 \%$ (Figure 3). The difference in the percentage of correctly staged cases by $\mathrm{CT}$ and by thoracoscopy compared by $\chi^{2}$ test $(139.11)$ was statistically significant $(P<.0001)$.

Considering $\mathrm{T}$ descriptor, the rate of understaging, correct staging, and overstaging by VATS was $3.8 \%, 96.2 \%$, and $0 \%$, respectively, compared with final pathologic staging. The same $\mathrm{T}$ parameter preoperatively evaluated by $\mathrm{CT}$ had been understaged, correctly staged, and overstaged in $12 \%, 85.6 \%$, and $0.1 \%$. The difference between CT and thoracoscopy in evaluating $\mathrm{T}$ descriptor was highly significant $\left(\chi^{2} 254.0 ; P<.0001\right)$.

Regarding $\mathrm{N}$ status, the rate of understaging, correct staging, and overstaging by VATS was $23 \%, 77 \%$, and $0 \%$, respectively. At preoperative CT the rate had been $15.5 \%$, $63.7 \%$, and $20.8 \%$, respectively. The difference was statistically significant $\left(\chi^{2} 504 ; P<.0001\right)$.

Considering the 58 patients in whom thoracoscopy revealed an unanticipated cause of inoperability and the
449 patients in whom thoracoscopy verified the feasibility of a VATS resection, thoracoscopy spared an unnecessary thoracotomy in $507(38.8 \%)$ patients.

\section{DISCUSSION}

Accurate staging is essential to the appropriate management of NSCLC, inasmuch as it predicts the prognosis and guides strategic planning of treatment. Preoperative staging is aimed at defining the nature, the size and local extension of the tumor, lymph nodal status, and possible metastases. Distant metastasis are usually adequately assessed in about $90 \%$ of patients by combining abdominal CT, brain CT or MRI, and bone scan or whole body PET. ${ }^{1}$

CT of the chest plays a central role in locoregional staging, inasmuch as it provides key information about size of the tumor and invasion of the fissures, the chest wall, or the mediastinum. ${ }^{10}$ Unfortunately, in many cases CT cannot precisely define the relationships between the tumor and the surrounding structures. In particular, CT is not always able to distinguish between simple contact and actual infiltration. 
A

\begin{tabular}{|c|c|c|c|c|c|c|c|c|}
\hline & \multicolumn{7}{|c|}{ Pathologic staging } \\
\hline & & IA & IB & IIA & III & IIIA & IIIB & IV \\
\hline \multirow{9}{*}{ 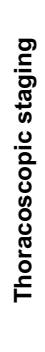 } & IA (292 pts) & 226 & 0 & 23 & 0 & 43 & 0 & 0 \\
\hline & IB (433 pts) & 0 & 309 & 0 & 65 & 56 & 3 & 0 \\
\hline & $\| \mathbf{A}(33 \mathrm{pts})$ & 0 & 0 & 33 & 0 & 0 & 0 & 0 \\
\hline & IIB (239 pts) & 0 & 0 & 0 & 162 & 56 & 21 & 0 \\
\hline & IIIA (12 pts) & 0 & 0 & 0 & 0 & 12 & 0 & 0 \\
\hline & IIIB (27 pts) & 0 & 0 & 0 & 0 & 0 & 27 & 0 \\
\hline & IV (32 pts) & 0 & 0 & 0 & 0 & 0 & 0 & 32 \\
\hline & & & & & & & & \\
\hline & Unfeasible (25 pts) & 0 & 0 & 0 & 1 & 7 & 17 & 0 \\
\hline
\end{tabular}

B

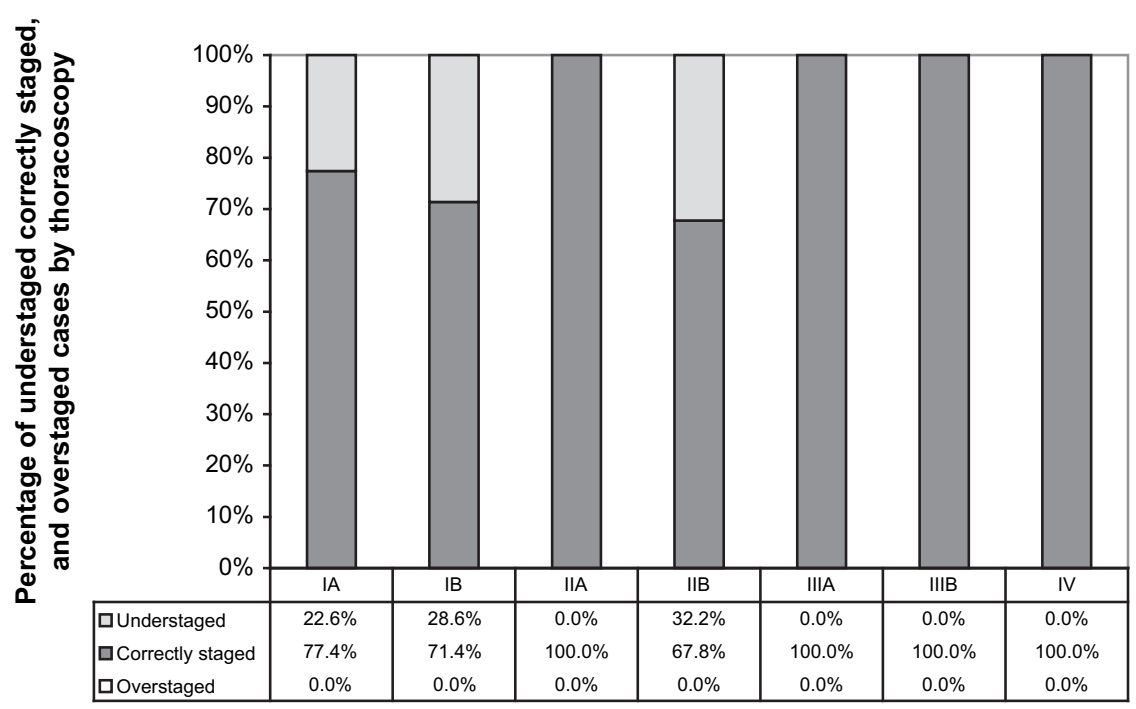

TNM Stages

FIGURE 3. A, TNM stages identified at thoracoscopic exploration compared with final pathologic staging. Dark gray cells indicate cases correctly staged by thoracoscopy, light gray cells indicate understaged cases, and white cells indicate overstaged cases. B, The percentage of correctly staged, understaged, and overstaged cases for each TNM stage identified by thoracoscopy, using the final pathologic staging as the benchmark.

In our experience, $\mathrm{T}$ parameter was correctly staged by preoperative $\mathrm{CT}$ in $85.6 \%$ of cases. According to other recent reports comparing $\mathrm{CT}$ findings with pathologic staging, $\mathrm{T}$ description was accurate in only $24 \%$ to $71 \%$ of cases. ${ }^{11,12}$ Therefore "patients should not be denied the opportunity for curative surgery on the basis of equivocal CT signs." ${ }^{, 13}$ Furthermore, pleural carcinosis with very small nodules and without pleural effusion usually goes undetected by CT. Concerning mediastinal staging, a recent meta-analysis reported pooled sensitivity of $57 \%$ and specificity of $82 \%$ with a positive predictive value of $56 \%$ and a negative predictive value of $83 \%{ }^{1}$

Recent metabolic imaging techniques such as FDG-PET or combined PET-CT have provided additional useful information on tumor activity and extension. From a wide metaanalysis, FDG-PET was more accurate than CT in evaluating mediastinal lymph node involvement. ${ }^{14}$ In particular, a negative PET is considered highly reliable in excluding mediastinal lymph node metastasis, ${ }^{1}$ and many authors suggest that a negative mediastinal PET, with no lymph nodal enlargement at $\mathrm{CT}$, justifies the abstention from further invasive surgical staging. ${ }^{10}$ Mediastinoscopy has long been the gold standard and still remains a very important tool for staging mediastinal lymph nodes. However, although pretracheal nodes (stations 1 and 3), paratracheal nodes (stations 2 and 4), and anterior subcarinal nodes are accessible through this technique, inferior mediastinal stations (stations 8 and 9) and aortopulmonary window and anterior mediastinal nodes (stations 5 and 6) cannot be reached and sampled. ${ }^{15}$

Thoracoscopy provides optimal access to mediastinal stations 5, 6, 7, 8, and 9 and also to ipsilateral pretracheal and paratracheal nodes, but contralateral lymphnodes can be evaluated only by bilateral video exploration. ${ }^{8,16,17}$

Notwithstanding improvement in conventional diagnostic tools, final staging still depends on surgical exploration and 
on pathologic specimens. Not infrequently, surgery reveals unexpected causes of inoperability and the procedure still ends in a failed thoracotomy owing to the presence of metastatic pleural deposits or infiltration of the mediastinum or vascular structures..$^{1-7}$ We believe that VATS exploration as the first step of the planned operation ensures thorough exploration of the pleural cavity and permits adequate evaluation of hilar and mediastinal tissue and of ipsilateral lymph node stations. The procedure is a valid substitute for thoracotomy exploration, but greatly reduces surgical trauma.

A number of authors have confirmed the efficacy of videothoracoscopic exploration for discovering small-nodule pleural dissemination, for evaluating the infiltration of the mediastinum, the artery within the fissure, or to reliably assess mediastinal lymph nodes. ${ }^{8,18-20}$ In our experience, video exploration proved useful in revealing causes of inoperability and highly reliable in excluding conditions of unresectability, with a negative predictive value of $97 \%$.

In the present study, thoracoscopy has resulted in a high rate of correctly staged lesions $(73.3 \%)$, significantly $(P<$ $.0001)$ superior to CT (48.7\%) (Figures 2 and 3 ). In describing $\mathrm{T}$ indicator, thoracoscopy proved very accurate $(96.2 \%$ of correctly staged cases), although it was less accurate $(77 \%)$ in evaluating $\mathrm{N}$ status. These findings are consistent with the literature. ${ }^{11}$

The status of mediastinal lymph nodes can change treatment strategy, depending on the surgeon's approach to N2 disease. In our department, $\mathrm{N} 2$ lesions suggested by preoperative $\mathrm{CT}$ are histologically confirmed and subjected to neoadjuvant treatment. Unexpected N2 disease, discovered at operation, undergoes surgical resection followed by adjuvant therapy. Now that PET scanning is more readily available, we proceed directly with surgical removal in patients with negative mediastinal PET results and plan mediastinoscopy or thoracoscopy in patients with PET-positive mediastinal adenopathy. In some cases of suspected N2 or N3 disease, endobronchial ultrasonography and endoscopic ultrasonography are valid alternatives to mediastinoscopy or thoracoscopy, even if they are not yet extensively available in all centers.

We personally adopt videothoracoscopy as a routine procedure before the intended surgical resection, ${ }^{8,9}$ as do several other authors. ${ }^{11,21-24}$ In our experience, preliminary videothoracoscopy exploration of the pleural cavity revealed an undetected cause of inoperability in $32(2.5 \%)$ patients with pleural metastatic dissemination without pleural effusion, thus sparing a useless exploratory thoracotomy. Furthermore, VATS exploration avoided a useless thoracotomy in another $22(1.7 \%)$ patients in whom infiltration of mediastinal structures was found and in a further $4(0.3 \%)$ patients ineligible for pneumonectomy, in whom intrafissural invasion of the artery was ascertained. Overall video exploration spared exploratory thoracotomy in $58(4.4 \%)$ patients. Other authors, in a series of 650 patients with clinically staged resectable NSCLC, observed $7 \%$ of inoperable disease at thoracoscopy, mainly owing to pleural metastasis or direct invasion of vital structures. ${ }^{25}$ The rate of exploratory thoracotomies after conventional staging in the literature ranges from $3 \%$ to $25 \% .^{2-7}$ In a previous analysis of our experience of more than 2000 pulmonary resections carried out between 1967 and 1980, the rate of exploratory thoracotomy had been $19 \%$ but had decreased to $11.6 \%$ in the $1980 \mathrm{~s}$ (1980-1991), after the progressive introduction of CT scanning in preoperative evaluation. ${ }^{8}$ This observation was consistent with other experiences. ${ }^{3}$ In our latest series of patients, after the introduction of VATS exploration, the rate of exploratory thoracotomy was $2.5 \%$. The only relevant variation in patient selection protocol had been the adoption of systematic video exploration once a patient had been judged to have operable disease on the basis of conventional clinical staging. However, some other factors could have influenced the reduction of the exploratory thoracotomies. In fact, if we add to the $58(4.4 \%)$ cases in which thoracoscopy revealed an unanticipated cause of inoperability the $32(2.5 \%)$ cases in which an exploratory thoracotomy was done despite preliminary thoracoscopy, the exploratory thoracotomy rate would have been $6.9 \%$. The difference $(4.7 \%)$ between our previous $11.6 \%$ rate of exploratory thoracotomy and post-VATS rate could therefore be due to other factors.

A progressive decrease of failed thoracotomies is commonly retrieved in the literature. ${ }^{26,27}$ Inasmuch as we have not made major changes in the patient selection protocol other than the introduction of preliminary thoracoscopy, we can only infer the factors contributing to the improvement of the failed thoracotomy rate. We must point out that in the same years CT scanners have evolved, helical CT have become more extensively available, and radiologists have been supported by more sophisticated computerized processing of images. Furthermore, as it has been commonly observed over these years, ${ }^{26}$ we have recorded a progressive inversion from a prevalence of central squamous cell tumors to adenocarcinomas. In the present series, we observed $29.5 \%$ of squamous cell tumors and $49.7 \%$ of adenocarcinoma (including $9.4 \%$ of bronchoalveolar carcinomas). This could also have influenced the decreasing of failed thoracotomy rate.

Without VATS, the 58 patients found at videothoracoscopy to have unresectable disease would have undergone an exploratory thoracotomy. Furthermore, it should be pointed out that $449(34.4 \%)$ patients had a fully thoracoscopic resection after preliminary thoracoscopy had confirmed the feasibility of a minimally invasive operation. Thus, thoracoscopy spared $507(38.8 \%)$ unnecessary thoracotomies. However, 25 patients, for whom VATS had not been adequately carried out owing to diffuse pleural adhesions, incomplete lung collapse, and poorly developed fissure, finally underwent exploratory thoracotomy, despite preliminary thoracoscopy.

Our experience, therefore, suggests that thoracoscopy limits the rate of exploratory thoracotomies, but technical or anatomic conditions can impair adequate exploration. 
When video exploration showed unequivocal causes of unresectability, the procedure was concluded, whereas it was converted to thoracotomy in any case of doubt. VATS is an invaluable tool in sparing unnecessary thoracotomies when it finds unequivocal signs of unresectable tumor, but sometimes open exploration is necessary to assess resectability, especially when an extensive dissection from delicate vital structures is required. This is a limitation of VATS exploration, although our experience suggests that in these cases, assessing inoperability was very difficult even after conversion to thoracotomy.

Validity of the thoracoscopic mediastinal staging has already been proved, ${ }^{8,16,17}$ but the impact on surgical strategy is more debatable inasmuch as it is related to the attitude of the surgical team toward N2 disease. Indeed, the approach to $\mathrm{N} 2$ disease has been changing over the past 15 years. Even if most surgeons prefer submitting patients with N2 disease to neoadjuvant therapy, some respected experts still maintain a different approach. The extensive adoption of PET scanning will probably change strategies over the next years. In experienced hands, preliminary video exploration adds only a short time to procedures. Pleural dissemination is readily detected, whereas the evaluation of mediastinal structures can require a longer time, especially when the tumor is in close contact with vital structures. In other instances, the maneuvers for evaluating resectability or actually dissecting the tumor to perform a videoendoscopic resection are not clearly separated. We have not conducted a systematic comparison of the costs, but they are considerably limited by adopting reusable instruments, as only a couple of ports, scissors, and forceps are necessary to carry out the exploration. The video equipment is usually already present in the theater for many other thoracoscopic or laparoscopic procedure.

In our experience, preliminary thoracoscopy did not increase the morbidity and avoided a significant number of useless thoracotomies. This is even more important in patients with relatively poor cardiopulmonary function.

\section{Limitations to the Study}

Although the results are encouraging, we must also point out some limitations of our study. The main limitation is that this is simply a retrospective review of a series accumulated over a relatively long period in a single institution. The retrospective nature of the study may imply a potential bias in patient selection and a greater difficulty in precise reporting of clinical aspects such as descriptions of intraoperative findings and minor complications. The fact that the experience derives from a single institution adds homogeneity to the procedures performed but limits the general applicability or reproducibility of the findings. The relatively long period can entail progressive modifications of the imaging techniques and of the patient population, difficult to identify and measure. Finally, the evaluation of costs and time of the procedure, as well as postoperative hospital stay, largely depend on local situations that can change greatly. Even if nonstatististical comparison has been conducted between the present and our previous "historical" series, the crude datum of spared thoracotomies (undetectable pleural minute pleural disseminations without effusion and resections carried out thoracoscopically) is self-evident.

In our opinion, $40 \%$ of spared thoracotomies is a very appreciable result, especially taking into account that preliminary exploration did not add morbidity or mortality and is, in most instances, a rapid procedure at reasonable costs. The magnitude of this impact, however, largely depends on the aggressiveness of the surgeon in performing a thoracoscopic resection. We must recall that despite our strong belief in the thoracoscopic approach, since the beginning of our experience we adopted very strict criteria for choosing to carry out a major resection for cancer by thoracoscopy, waiting for confirmation of the long-term oncologic validity of the procedure. ${ }^{28}$ In fact, we deliberately converted to open resection several lobectomies that could have been technically possible by thoracoscopy. The proportion of patients indicating a VATS sublobar resection owing to poor conditions will also affect the impact of the strategy. VATS lobectomies are no longer experimental procedures and are increasingly performed even among general thoracic surgeons who do not work in specifically dedicated institutions. According to a recent report based on the Society of Thoracic Surgeons database, up to $20 \%$ of lobectomies have been performed as a VATS operation, and the article does not include the rate of sublobar resections carried out thoracoscopically. ${ }^{29}$ All these considerations lead to the possibility of an ever-increasing impact of minimally invasive techniques in NSCLC management.

\section{CONCLUSIONS}

In our opinion, even considering that videothoracoscopy has not changed the management in more than $50 \%$ of patients, the clinical benefit of sparing an unnecessary thoracotomy in $40 \%$ of patients is worthwhile (especially in frail patients), performing a preliminary thoracoscopy to rule out causes of inoperability or to decide whether resection can be carried out through videothoracoscopic or conventional procedures. On these bases and with these caveats, we would recommend an extensive adoption of videothoracoscopic exploration as the initial step of the planned operation.

\section{References}

1. Toloza EM, Harpole L, McCrory DC. Noninvasive staging of non-small cell lung cancer. A review of the current evidence. Chest. 2003;123:137S-46S.

2. Laroche C, Wells F, Coulden R, Stewart S, Goddart M, Lowry E, et al. Improving surgical resection rate in lung cancer. Thorax. 1998;53:445-9.

3. Steinbaum SS, Uretzky ID, McAdams HP, Torrington KG, Cohen AJ. Exploratory thoracotomy for non-resectable lung cancer. Chest. 1995;107:1058-61.

4. Weiman DS, Bolton JWR, Howard ML, Olsen GN, Almond CH, Greene FL. Failure of preoperative staging to assess unresectability in M0 bronchogenic carcinoma. Cancer. 1989;63:767-8.

5. Naruke T, Goya T, Tsuchiya R, Suemasu K. Prognosis and survival in resected lung carcinoma based on the new international staging system. J Thorac Cardiovasc Surg. 1988;96:440-7. 
6. Deneffe G, Lacquet LM, Verbeken E, Vermaut G. Surgical treatment of bronchogenic carcinoma: a retrospective study of 720 thoracotomies. Ann Thorac Surg. 1988;45:380-3.

7. Van Den Bosch JMM, Gelissen HJ, Wagenaar SS. Exploratory thoracotomy in bronchial carcinoma. J Thorac Cardiovasc Surg. 1983;85:733-7.

8. Roviaro GC, Varoli F, Rebuffat C, Vergani C, Maciocco M, Scalambra SM, et al. Videothoracoscopic staging and treatment of lung cancer. Ann Thorac Surg. 1995;59:971-4.

9. Roviaro GC, Varoli F, Rebuffat C, Sonnino D, Vergani C, Maciocco M, et al. Videothoracoscopic operative staging for lung cancer. Int Surg. 1996;81:252-4.

10. Verschakelen JA, De Wever W, Bogaert J. Role of computed tomography in lung cancer staging. Curr Opin Pulm Med. 2004;10:248-55.

11. Roberts JR, Blum MG, Arildsen R, Drinkwater DC Jr, Christian KR, Powers TA, et al. Prospective comparison of radiologic, thoracoscopic and pathologic staging in patients with early non-small cell lung cancer. Ann Thorac Surg. 1999;68:1154-8.

12. Sioris T, Järvenpää R, Kuukasjärvi P, Helin H, Saarelainen S, Tarkka M. Comparison of computed tomography and systemic lymph node dissection in determining TNM and stage in non-small cell lung cancer. Eur J Cardiothorac Surg. 2003;23: 403-8.

13. White PG, Adams H, Crane MD, Butchart EG. Preoperative staging of carcinoma of the bronchus: can computed tomographic scanning reliably identify stage III tumors? Thorax. 1994;49:951-7.

14. Gould MK, Kuschner WG, Rydzak CE, Maclean CC, Demas AN, Shigemitsu H, et al. Test performance of positron emission tomography and computed tomography for mediastinal staging in patients with non-small-cell lung cancer: a metaanalysis. Ann Intern Med. 2003;139:879-92.

15. Detterbeck FC, DeCamp MM, Kohman LJ, Silvestri GA. Invasive staging. The guidelines. Chest. 2003;123:167S-75S.

16. Landreneau RJ, Hazelrigg SR, Mack MJ, Fitzgibbon LD, Dowling RD, Acuff TE, et al. Thoracoscopic mediastinal lymph node sampling useful for mediastinal lymph node stations inaccessible by cervical mediasinoscopy. J Thorac Cardiovasc Surg. 1993;106:554-8.

17. Ishida T, Ishi T, Yamazaki K, Ondo K, Yamamoto K, Kido A, et al. Thoracoscopic limited resection of bronchogenic carcinoma in patients over the age of 80. Int Surg. 1996;81:237-40.
18. Champion JK, McKernan JB. Comparison of minimally invasive thoracoscopy versus open thoracotomy for staging lung cancer. Int Surg. 1996;81:235-6.

19. De Giacomo T, Rendina EA, Venuta F, Della Rocca G, Ricci C. Thoracoscopic staging of IIIB non-small cell lung cancer before neoadjuvant therapy. Ann Thorac Surg. 1997;64:1409-11.

20. Loscertales J, Jiménez-Merchán R, Congregado-Loscertales M, ArenasLinares C, Girón-Arjona JC, Tristan AA, et al. Usefulness of videothoracoscopic intrapericardial examination of pulmonary vessels to identify resectable clinical T4 lung cancer. Ann Thorac Surg. 2002;73:1563-6.

21. Yim APC. VATS major pulmonary resection revisited-controversies, techniques, and results. Ann Thorac Surg. 2002;74:615-23.

22. Asamura H, Nakayama H, Kondo H, Tsuchiya R, Naruke T. Thoracoscopic evaluation of histologically/cytologically proven or suspected lung cancer: a VATS exploration. Lung Cancer. 1997;16:183-90.

23. Wain JC. Video-assisted thoracoscopy and the staging of lung cancer. Ann Thorac Surg. 1993;56:776-8.

24. Loscertales J, Jimenez-Merchan R, Arenas-Linares C, Giron-Arjona JC, Congregado-Loscertales $\mathrm{M}$. The use of videoassisted thoracic surgery in lung cancer: evaluation of resectability in 296 patients and 71 pulmonary exeresis with radical lymphadenectomy. Eur J Cardiothorac Surg. 1997;12:892-7.

25. Sonett JR, Krasna MJ. Thoracoscopic staging for intrathoracic malignancy. In Yim APC, Hazelrigg SR, Izzat MB, Landreneau RJ, Mack MJ, Naunheim KS, eds. Minimal access cardiothoracic surgery. Philadelphia: WB Saunders; 2000.p.183-93.

26. Wada H, Tanaka F, Yanagihara K, Ariyasu T, Fukuse T, Yokomise H, et al. Time trends and survival after operations for primary lung cancer from 1976 through 1990. J Thorac Cardiovasc Surg. 1996;112:349-55.

27. Jie C, Wever AMJ, Huysmans HA, Franken HCM, Wever-Hess J, Hermans J. Time trends and survival in patients presented for surgery with non-small-cell lung cancer 1969-1985. Eur J Cardiothorac Surg. 1990;4:653-7.

28. Roviaro GC, Varoli F, Vergani C, Nucca O, Maciocco M, Grignani F. Long-term survival after videothoracoscopic lobectomy for stage I lung cancer. Chest. 2004; 126:725-32.

29. Boffa DJ, Allen MS, Grab JD, Gaissert HA, Harpole DH, Wright CD. Data from the Society of Thoracic Surgeons General Thoracic Surgery database: the surgical management of primary lung tumors. J Thorac Cardiovasc Surg. 2008;135:247-54. 